\title{
Role of tRNA selenocysteine 1 associated protein 1 in the proliferation and apoptosis of cardiomyocyte-like $\mathrm{H} 9 \mathrm{c} 2$ cells
}

\author{
MENG-DI LI, WAN-PENG CHENG, MIN-XIA SHI, TANG-DONG GE, XIAO-LIN ZHENG, \\ DONG-YUAN WU, XIAO-YAN HU, JIN-CHENG LUO, FENG-LAN LI and HUI LI
}

Department of Biochemistry and Molecular Biology, Harbin Medical University, Harbin, Heilongjiang 150081, P.R. China

Received November 12, 2015; Accepted November 22, 2016

DOI: $10.3892 / \mathrm{mmr} .2016 .6099$

\begin{abstract}
Transfer RNA selenocysteine 1 associated protein 1 (Trnaulap) serves an essential role in the synthesis of selenoproteins, which have critical functions in numerous biological processes. Selenium deficiency results in a variety of diseases, including cardiac disease. However, the mechanisms underlying myocardial injury induced by selenium deficiency remain unclear. The present study examined the effects of Trnaulap under- and overexpression in cardiomyocyte-like H9c2 cells, by transfection with small interfering RNA and an overexpression plasmid, respectively. Expression levels of glutathione peroxidase, thioredoxin reductase and selenoprotein $\mathrm{K}$ were decreased in Trnaulap-underexpressing cells, and increased in Trnaulap-overexpressing cells. Using MTT, proliferating cell nuclear antigen, annexin $\mathrm{V}$ and caspase-3 activity assays, it was demonstrated that reducing Trnaulap expression levels inhibited the proliferation of $\mathrm{H} 9 \mathrm{c} 2$ cells and induced apoptosis. Conversely, increasing Trnaulap expression levels promoted cell growth. Western blot analysis revealed that the phosphoinositide 3-kinase/protein kinase B signaling pathway was activated in Trnaulap-underexpressing cells. Furthermore, the apoptotic pathway was activated in these cells, evidenced by relatively greater expression levels of B-cell lymphoma (Bcl-2)-associated X protein and reduced expression levels of Bcl-2. Taken together, these findings suggest that Trnaulap serves a key role in the proliferation and apoptosis of $\mathrm{H} 9 \mathrm{c} 2$ cells. The present study provides insight into the underlying mechanisms of myocardial injury induced by selenium deficiency.
\end{abstract}

Correspondence to: Professor Hui Li, Department of Biochemistry and Molecular Biology, Harbin Medical University, 194 Xuefu Road, Harbin, Heilongjiang 150081, P.R. China

E-mail: lihui@ems.hrbmu.edu.cn

Key words: cardiomyocyte-like cells, transfer RNA selenocysteine 1 associated protein 1 , apoptosis, proliferation, phosphoinositide 3-kinase/protein kinase B pathway

\section{Introduction}

Selenium was discovered by the Swedish chemist Jöns Jacob Berzelius in 1817. It was considered a toxin until 1957, when the trace element was identified as an essential micronutrient for animals and humans $(1,2)$. Selenium serves a role in numerous biological processes, including immune function, brain development and reproduction $(3,4)$. In vivo, selenium is found in selenoproteins, which co-translationally incorporate selenium-containing selenocysteine ( $\mathrm{Sec}$ ), the 21st genetically encoded amino acid $(5,6)$. Selenoproteins are critical for numerous physiological functions, including antioxidant defense, thyroid hormone production (4) and inflammation and immunity (7). Primary selenoproteins include glutathione peroxidases (GPxs), thioredoxin reductases (TrxRs) and iodothyronine deiodinases $(8,9)$. Sec and selenoprotein biosynthesis requires a multitude of protein factors, including Sep (O-phosphoserine) transfer (t)RNA:Sec (selenocysteine) synthase (SepSecS), tRNA Sec 1 associated protein 1 (Trnaulap), and Sec insertion sequence binding protein 2 (SBP2) (10).

Trnaulap, originally named SECp 43 , is a highly conserved 43-kDa tRNA ${ }^{[\mathrm{Ser}]}$ Sec-binding protein identified by affinity purification (11). It has been identified to interact with the selenocysteyl-tRNA ${ }^{[\mathrm{Ser}] \mathrm{Sec}}$-Sec-specific elongation factor $(\mathrm{EFsec})$ complex in vitro, and co-expression of Trnaulap facilitates interaction between EFsec and SBP2 in vivo. In addition, Trnaulap mediates Sec incorporation and upregulates selenoprotein mRNA expression levels (12). Furthermore, when SepSecS and Trnaulap are co-expressed in vitro, Trnaulap induces SepSecS to localize to the cytoplasm rather than the nucleus, where Trnaulap typically resides (13). A previous study demonstrated that downregulation of Trnaulap and SepSecS resulted in an extensive reduction of selenoprotein expression levels, whereas downregulation of SepSecS alone had no effect. Additionally, downregulation of Trnaulap reduced GPx1 expression levels (14). These findings suggest that Trnaulap serves a key role in the biosynthesis of selenoproteins.

Selenium deficiency results in a variety of cardiovascular diseases, including Keshan disease. Keshan disease, a cardiomyopathy endemic to China, is characterized by heart failure and severe cardiomyopathy, typically with arrhythmia and congestive heart failure $(15,16)$. Our previous study 
demonstrated that reactive oxygen species accumulation and myocardial injury were features of a mouse model of selenium deficiency (17). However, the underlying mechanisms of myocardial injury induced by selenium deficiency remain unclear.

The present study hypothesized that Trnaulap may participate in selenium deficiency-induced myocardial injury. The role of Trnaulap in myocardial cell proliferation and apoptosis was investigated using $\mathrm{H} 9 \mathrm{c} 2$ cells. Furthermore, the phosphoinositide 3-kinase (PI3K)/protein kinase B (AKT) signaling pathway was examined to provide further insight into the molecular mechanisms underlying cardiomyocyte injury.

\section{Materials and methods}

Cell culture. The H9c2rat cardiac myoblast cell line (purchased from the American Type Culture Collection, Manassas, VA, USA), was maintained in Dulbecco's modified Eagle's medium (DMEM; Invitrogen; Thermo Fisher Scientific, Inc., Waltham, MA, USA) containing $5.5 \mathrm{mM}$ glucose supplemented with $10 \%$ fetal bovine serum (Biological Industries, Kibbutz Beit Haemek, Israel) and $100 \mathrm{U} / \mathrm{ml}$ penicillin/streptomycin (Biological Industries) in an atmosphere of $5 \% \mathrm{CO}_{2}$ at $37^{\circ} \mathrm{C}$.

Plasmids, small interfering (si)RNA and transfection. The open reading frame of Trnaulap was cloned into a pcDNA3.1(+) vector (pcDNA3.1(+)-Trnaulap; Thermo Fisher Scientific, Inc.), and transfection was performed using Lipofectamine ${ }^{\circledR}$ 2000 (Thermo Fisher Scientific, Inc.) according to the manufacturer's protocol, when cells were at $70-80 \%$ confluence. H9c2 cells transfected with the empty vector (H9c2-mock) or pcDNA3.1(+)-Trnaulap (H9c2-Trnaulap) were analyzed 24-72 h post-transfection. A total of three siRNAs targeting Trnaulap were obtained from Guangzhou RiboBio Co., Ltd. (Guangzhou, China). The sequences were as follows: 5'-GCC GAGAAGTGTTTGCATA-3' (Trnaulap siRNA-1), 5'-GGA CGAUGGCAUGCUGUAU-3' (Trnaulap siRNA-2) and 5'-GCAGACAUAUGAAGAGGUU-3' (Trnaulap siRNA-3). A negative control siRNA was additionally obtained from Guangzhou RiboBio Co., Ltd. Transfection was conducted using Lipofectamine 2000 according to the manufacturer's protocol, when cells were at $60-70 \%$ confluence. Analysis was conducted $24-72 \mathrm{~h}$ post-transfection.

RNA extraction and reverse transcription-quantitative polymerase chain reaction ( $R T-q P C R)$. Total RNA samples were isolated from cells $24 \mathrm{~h}$ post-transfection with TRIzol ${ }^{\circledR}$ (Thermo Fisher Scientific, Inc.) and reverse transcribed into cDNA using the High-Capacity cDNA RT kit (Applied Biosystems; Thermo Fisher Scientific, Inc.), according to the manufacturer's protocol. qPCR was performed using SYBR ${ }^{\circledR}$ Green PCR Master mix and the 7500Real-Time PCR system (Applied Biosystems; Thermo Fisher Scientific, Inc.). The primers for Trnaulap were as follows: Forward, 5'-AGGTTG GGGATGATGCACTG-3' and reverse, 5'-CGGGGATCTCTG ATGACACG-3'. Rat $\beta$-actin served as the endogenous control, with the following primer sequences: Forward, 5'-CCACCA TGTACCCAGGCATT-3' and reverse, 5'-CGGACTCATCGT ACTCCTGC-3'. The PCR was performed with an initial stage of $95^{\circ} \mathrm{C}$ for $10 \mathrm{~min}$, followed by 40 cycles of $95^{\circ} \mathrm{C}$ for $15 \mathrm{sec}$ and elongation at $60^{\circ} \mathrm{C}$ for $30 \mathrm{sec}$. A dissociation curve was run for each plate to confirm the production of a single product. All assays were performed in triplicate. The relative RNA expression levels were determined using the $2^{-\Delta \Delta \mathrm{Cq}}$ method (18).

Western blotting. Total protein samples were extracted from cells $72 \mathrm{~h}$ post-transfection using radioimmunoprecipitation assay lysis buffer (EMD Millipore, Billerica, MA, USA). Following incubation at $4^{\circ} \mathrm{C}$ for $15 \mathrm{~min}$, the lysates were centrifuged at $6,000 \times \mathrm{g}$ for $10 \mathrm{~min}$ at $4^{\circ} \mathrm{C}$. Protein concentrations were determined using the Bicinchoninic Acid Assay kit (Pierce; Thermo Fisher Scientific, Inc.). Samples $(50 \mu \mathrm{g})$ were mixed with loading buffer, denatured for $5 \mathrm{~min}$ at $95^{\circ} \mathrm{C}$ and separated by $12 \%$ SDS-PAGE. The separated proteins were transferred onto polyvinylidene difluoride membranes (EMD Millipore), blocked with 5\% non-fat milk in Tris-buffered saline/Tween- 20 for $2 \mathrm{~h}$ at $25^{\circ} \mathrm{C}$, and incubated with antibodies for $12 \mathrm{~h}$ at $4^{\circ} \mathrm{C}$. The following primary antibodies were used: rabbit anti-Trnaulap (1:1,000; catalog no. 15053-1-AP), rabbit anti-PCNA $(1: 1,000$; catalog no. 10205-2-AP) and rabbit anti-Bax (1:1,000; catalog no. 50599-2-Ig) from ProteinTech Group, Inc. (Chicago, IL, USA); rabbit anti-selenoprotein K (SelK; 1:1,000; catalog no. ab139949) and rabbit anti-thioredoxin reductase 1 (Txnrd1; 1:1,000; catalog no. ab16840) from Abcam (Cambridge, MA, USA); rabbit anti-GPx1 (1:1,000; catalog no. PA5-30593; Thermo Fisher Scientific, Inc.); rabbit anti-Bcl-2 (1:1,000; catalog no. B0774; Assay Biotechnology, Sunnyvale, CA, USA); rabbit anti-AKT $(1: 1,000$; catalog no. 9272) and rabbit anti-phosphorylated (p)-AKT (1:1,000; catalog no. 4058) from Cell Signaling Technology, Inc. (Danvers, MA, USA); and mouse anti- $\beta$-actin $(1: 1,000$; catalog no. BM0627, Boster Biological Technology, Wuhan, Hubei, China). The secondary antibodies used were goat anti-rabbit horseradish peroxidase (HRP)-conjugated IgG (1:2,000; catalog no. ZB-2301) and goat anti-mouse HRP IgG (1:2,000; catalog no. ZB-2305) purchased from Zhongshan Golden Bridge Biotechnology, Co., Ltd. (Beijing, China). The membranes were incubated with the secondary antibodies for $2 \mathrm{~h}$ at room temperature. The signals were detected by BioSpectrum 810 Imaging system (UVP, LLC, Upland, CA, USA) using enhanced chemiluminescence system (Pierce ECL Western Blotting substrate; Thermo Fisher Scientific, Inc.). The relative densities of bands were analyzed with Quantity One 4.62 software (Bio-Rad Laboratories, Inc., Hercules, CA, USA).

Cell proliferation assays. A total of $24 \mathrm{~h}$ post-transfection with siRNA or plasmid, H9c2 cells were seeded into 96-well plates at a density of 2,000 viable cells per well for cell proliferation assays, which were performed using 3-[4,5-dimethylthiazol-2-yl]-2,5-diphenyltetrazoliumbromide (MTT; Sigma-Aldrich; Merck Millipore, Darmstadt, Germany), diluted to $5 \mathrm{mg} / \mathrm{ml}$ with serum-free DMEM. A total of $48 \mathrm{~h}$ after seeding, MTT was added to each well and incubated for $4 \mathrm{~h}$ at $37^{\circ} \mathrm{C}$. Formazan crystals were dissolved in dimethyl sulfoxide, and absorbance at a wavelength of $490 \mathrm{~nm}$ was measured using a SpectraMax ${ }^{\circledR}$ M3microplate spectrophotometer (Molecular Devices, LLC, Sunnyvale, CA, USA). 
Flow cytometry. A total of $1 \times 10^{6}$ cells were seeded into a $60-\mathrm{mm}$ dish $24 \mathrm{~h}$ prior to the experiment. A total of $48 \mathrm{~h}$ post-transfection, annexin V-fluorescein isothiocyanate (FITC) and propidium iodide (PI) staining were performed according to the manufacturer's protocol (Beyotime Institute of Biotechnology, Haimen, China). The stained cells were acquired using a FACSCalibur ${ }^{\mathrm{TM}}$ Flow Cytometer (BD Biosciences, Franklin Lakes, NJ, USA). All data were analyzed and visualized using FACSDiva ${ }^{\mathrm{TM}} 3.0$ software (BD Biosciences).

Caspase-3 activity. Caspase-3 activity was determined using the Caspase-3 Activity assay kit (Beyotime Institute of Biotechnology), according to the manufacturer's protocol. Assays were conducted in 96-well microplates by incubating $10 \mu \mathrm{l}$ cell lysate with $80 \mu \mathrm{l}$ reaction buffer (1\% NP-40, $20 \mathrm{mM}$ Tris- $\mathrm{HCl}$ at $\mathrm{pH} 7.5,137 \mathrm{mM} \mathrm{NaCl}$ and $10 \%$ glycerol) and $10 \mu \mathrm{l}$ $2 \mathrm{mM}$ caspase-3 substrate (Ac-DEVD-pNA). The lysates were incubated at $37^{\circ} \mathrm{C}$ for $4 \mathrm{~h}$. The absorbance of samples was measured at a wavelength of $405 \mathrm{~nm}$ using the SpectraMaxM3 microplate reader.

Mitochondrial membrane potential assay. Mitochondrial depolarization in the cells was measured using a Mitochondrial Membrane Potential assay kit with a JC-1 probe (Beyotime Institute of Biotechnology). Briefly, mitochondria were isolated from the cells following treatment, using the Cell Mitochondria Isolation kit (Beyotime Institute of Biotechnology), and incubated with $1 \mathrm{ml} \mathrm{JC}-1$ staining solution $(5 \mu \mathrm{g} / \mathrm{ml})$ for $20 \mathrm{~min}$ at $37^{\circ} \mathrm{C}$, and subsequently with phosphate-buffered saline. The mitochondrial membrane potentials were measured using the relative quantities of dual emissions from mitochondrial JC-1 monomers or aggregates using the SpectraMaxM3 microplate spectrophotometer. The excitation wavelength was set at $485 \mathrm{~nm}$. Fluorescence intensity was detected at wavelengths of $525 \mathrm{~nm}$ for monomers and $590 \mathrm{~nm}$ for aggregates. Mitochondrial depolarization was indicated by an increase in the $525 / 590 \mathrm{~nm}$ fluorescence intensity ratio.

Statistical analysis. All experiments were performed at least three times. Normal distribution data are presented as the mean \pm standard deviation, and differences between two groups were evaluated using the Student's $t$-test. One-way ANOVA followed by the Dunnett's multiple comparison test was used to examine differences of treated groups with the control group. $\mathrm{P}<0.05$ was considered to indicate a statistically significant difference. All statistical analyses were performed using SPSS software version 17.0 (SPSS, Inc., Chicago, IL, USA).

\section{Results}

Modulation of Trnaulap expression levels in H9c2 cells. A total of three different siRNAs targeting Trnaulap were transfected into H9c2 cells. After a 24-h incubation, the most effective siRNA (siRNA-1) was determined by RT-qPCR (Fig. 1A; P<0.001for H9c2-siRNA1 compared with H9c2; $\mathrm{P}<0.001$ for $\mathrm{H} 9 \mathrm{c} 2-$ siRNA2 compared with $\mathrm{H} 9 \mathrm{c} 2 ; \mathrm{P}<0.001$ for H9c2-siRNA3 compared with H9c2) and used for subsequent experiments. Western blotting analysis was performed
$48 \mathrm{~h}$ post-transfection to confirm under-and overexpression of Trnaulap in H9c2 cells, compared with the control siRNA or H9c2-mock groups, respectively (Fig. 1B, $\mathrm{P}<0.01$ compared with Control siRNA; Fig. 1C, $\mathrm{P}<0.05$ compared with H9c2-mock). Modulating Trnaulap expression levels affected GPx1, Txnrd1 and SelK expression levels, demonstrating that Trnaulap affects the expression levels of a variety of selenoproteins (Fig. 1D, $\mathrm{P}<0.05$ and $\mathrm{P}<0.01$ compared with Control siRNA; Fig. 1E, $\mathrm{P}<0.05$ and $\mathrm{P}<0.01$ compared with H9c2-mock).

Downregulation of Trnaulap inhibits the proliferation of $H 9 c 2$ cells. To examine whether Trnaulap affects the proliferation of $\mathrm{H} 9 \mathrm{c} 2$ cells, an MTT assay was performed and proliferating cell nuclear antigen (PCNA) expression levels were measured. Compared with the control group, cells transfected with Trnaulap siRNA exhibited decreased proliferation (Fig. 2A, P<0.05 compared with H9c2-siRNA). Conversely, Trnaulap-overexpressing cells exhibited increased proliferation, compared with mock-transfected cells (Fig. 2B, $\mathrm{P}<0.01$ compared with H9c2-mock). Expression levels of PCNA were reduced in Trnaulap-underexpressing cells, compared with control siRNA-transfected cells (Fig. 2C, P<0.05 compared with H9c2-siRNA), and increased in Trnaulap-overexpressing cells compared with control mock-transfected cells (Fig. 2D, $\mathrm{P}<0.05$ compared with H9c2-mock).

Downregulation of Trnaulap induces apoptosis. To examine the role of Trnaulap in apoptosis in $\mathrm{H} 9 \mathrm{c} 2$ cells, annexin V-FITC and PI double staining was performed, and flow cytometric analysis was performed to measure the apoptotic rate of cells (Fig. 3A and B, $\mathrm{P}<0.05$ compared with H9c2-siRNA). Compared with the control group, the apoptotic rate was increased in the Trnaulap siRNA-transfected group. No significant differences were observed in the apoptotic rates of cells between the Trnaulap overexpression and empty vector groups.

Additionally, a Caspase-3 Activity assay kit was used to evaluate the apoptotic status of the various groups. In the underexpression group, caspase-3 activity was markedly increased compared with the control group (Fig. 3C, $\mathrm{P}<0.01$ compared with H9c2-siRNA). In comparison, there were no significant differences between the overexpression and mock-transfected groups (Fig. 3C, $\mathrm{P}=0.08$ compared with $\mathrm{H} 9 \mathrm{c} 2$-mock).

A Mitochondrial Membrane Potential assay was performed using a JC-1 probe. In cells with healthy mitochondria, JC-1 is aggregated and emits a red fluorescence. When the inner mitochondrial membrane potential is dissipated, JC-1 is disaggregated and emits a green fluorescence. Therefore, depolarization of the mitochondrial membrane potential is detected as an increase in the green/red fluorescence ratio. The Trnaulap underexpression group exhibited a depolarization of the mitochondrial membrane potential (Fig. 3D, $\mathrm{P}<0.05$ compared with H9c2-siRNA), whereas no significant differences were observed between the overexpression and mock-transfected groups (Fig. 3D, $\mathrm{P}=0.0569$ compared with H9c2-mock).

To further examine the role of Trnaulap in cell death, two apoptosis-associated proteins, Bcl-2 and Bax, were examined by western blotting. Bax expression levels were upregulated, 
A

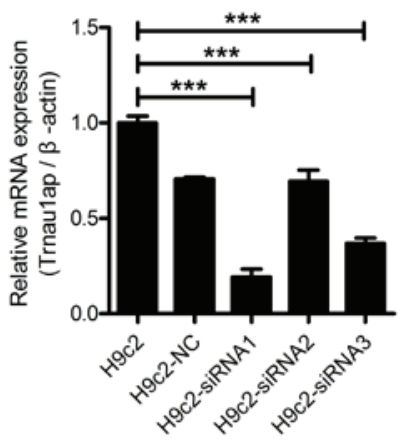

$\mathrm{D}$

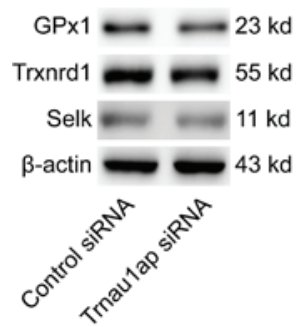

B
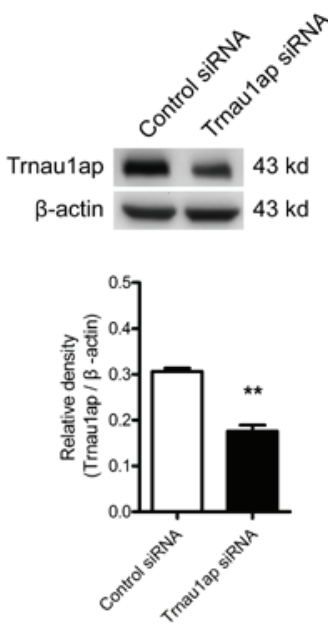

$\mathrm{C}$
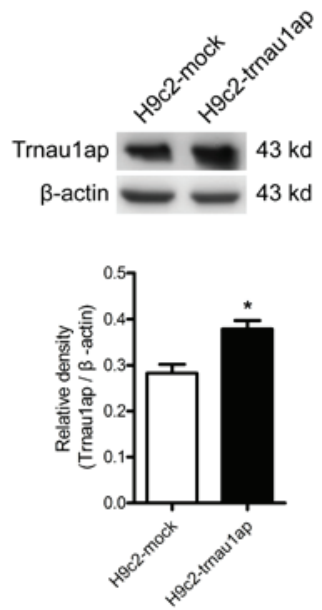

$\mathrm{E}$
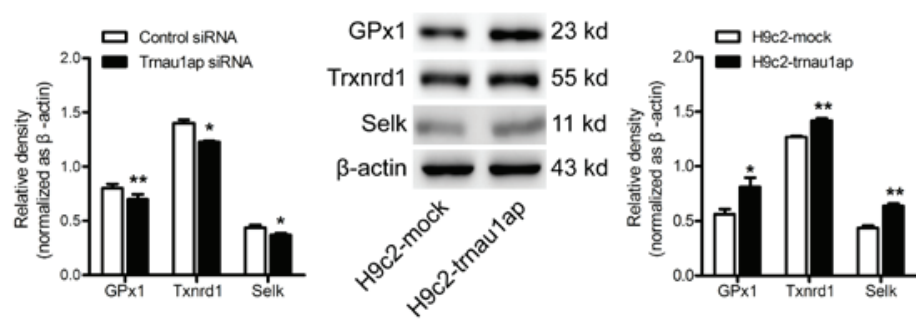

Figure 1. Expression levels of Trnaulap in H9c2 cells. (A) Expression levels of Trnaulap were determined by RT-qPCR 24 h post-transfection with Trnau1ap siRNAs or control siRNA. Western blot analysis of Trnaulap protein expression levels in (B) H9c2 cells transfected with Trnaulap siRNA or control siRNA for $48 \mathrm{~h}$ and (C) H9c2 cells transfected with empty vector or pcDNA 3.1(+)-Trnaulap, $48 \mathrm{~h}$ post-transfection. Western blot analysis of GPx1, Txnrd1 and SelK levels in (D) Trnaulap-underexpressing, and (E) Trnaulap-overexpressing, cells. $\beta$-actin served as an endogenous control for western blotting and RT-qPCR. All data are presented as the mean \pm standard deviation $(\mathrm{n}=3)$. ${ }^{*} \mathrm{P}<0.05,{ }^{* *} \mathrm{P}<0.01$ vs. control siRNA or H9c2-mock, ${ }^{* * * *} \mathrm{P}<0.001$. Trnau1ap, transfer RNA selenocysteine 1 associated protein 1; siRNA, small interfering RNA, GPx1, glutathione peroxidase 1; Txnrd1, thiorexin reductase 1; Selk, selenoprotein K; RT-qPCR, reverse transcription-quantitative polymerase chain reaction.

A

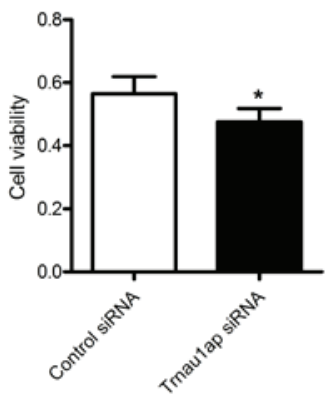

$\mathrm{C}$

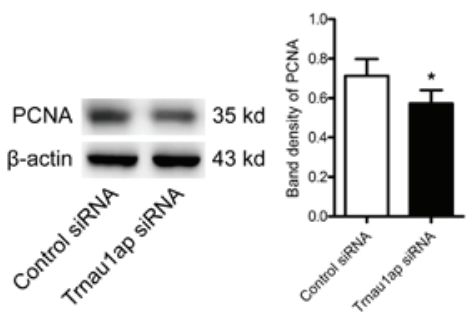

$\mathrm{B}$

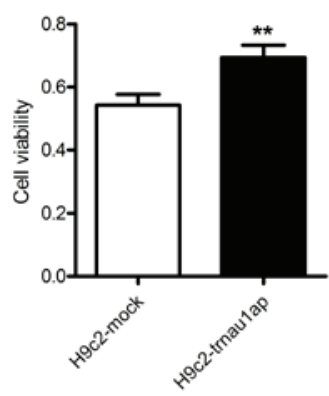

$\mathrm{D}$

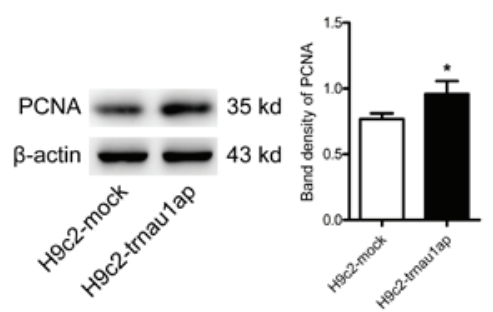

Figure 2. Effects of modulating Trnaulap expression levels on H9c2 cell proliferation. MTT assays were performed on cells with (A) Trnaulap knockdown by siRNA and (B) Trnaulap overexpression by Trnaulap transfection. Western blot analysis of protein expression levels of PCNA in (C) Trnaulap-underexpressing, and (D) Trnaulap-overexpressing, cells. $\beta$-actin served as an endogenous control. All data are presented as the mean \pm standard deviation $(n=3)$. ${ }^{*}<<0.05$ and ${ }^{* *} \mathrm{P}<0.01$ vs. control siRNA or H9c2-Mock. Trnaulap, transfer RNA selenocysteine 1 associated protein 1; siRNA, small interfering RNA; PCNA, proliferating cell nuclear antigen. 
A
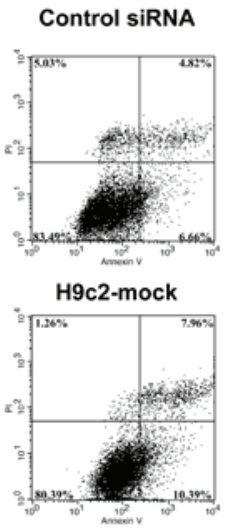

$\mathrm{C}$

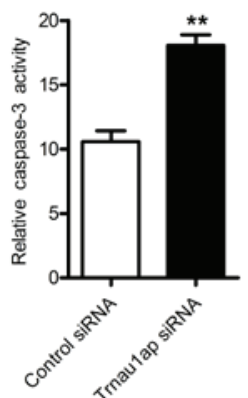

B
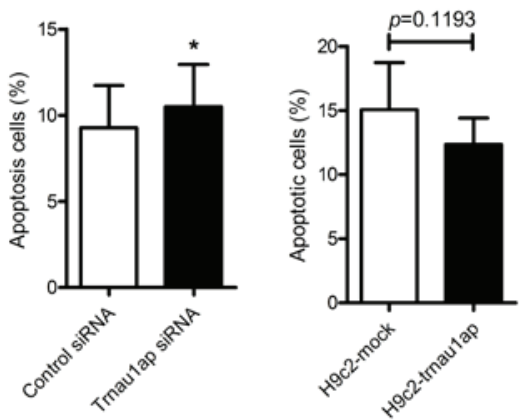

$\mathrm{D}$
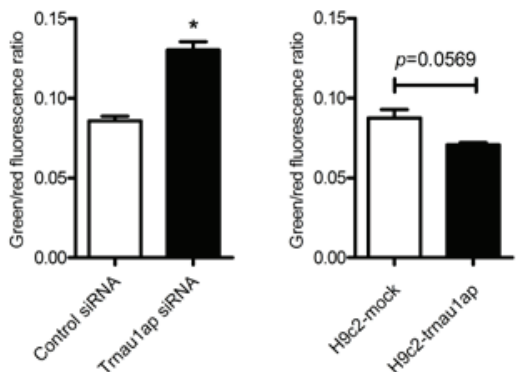

Figure 3. Effects of modulating Trnaulap expression levels on H9c2 cell apoptosis. (A) Apoptotic cells in the different groups were detected using annexin V-fluorescein isothiocyanate and PI staining $48 \mathrm{~h}$ post-transfection, and (B) the apoptotic rate was calculated. (C) Relative activity of caspase-3 in the different groups $48 \mathrm{~h}$ post-transfection. (D) Mitochondrial membrane potential in the four groups, measured using a JC-1 probe. Depolarization of the mitochondrial membrane potential is indicated as an increase in the green/red fluorescence ratio. All data are presented as the mean \pm standard deviation $(\mathrm{n}=3) .{ }^{*} \mathrm{P}<0.05$ and $^{* *} \mathrm{P}<0.01$ vs. control siRNA or H9c2-Mock. Trnaulap, transfer RNA selenocysteine 1 associated protein 1; siRNA, small interfering RNA; PI, propidium iodide; ns, non-significant.

A
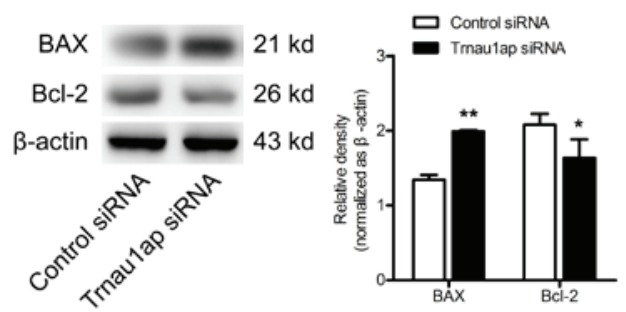

$\mathrm{C}$

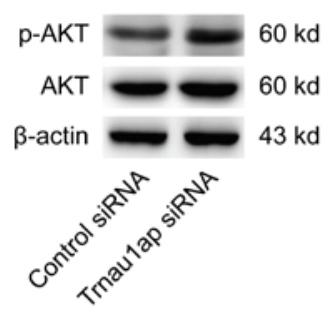

$\mathrm{B}$
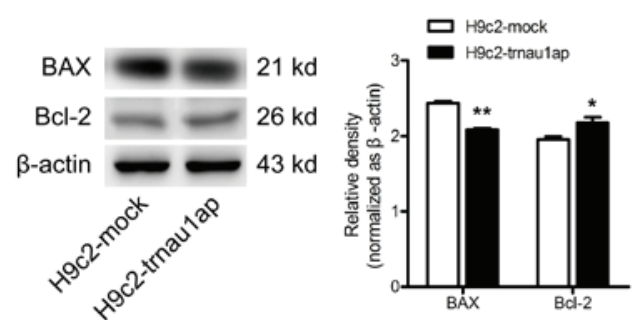

$\mathrm{D}$
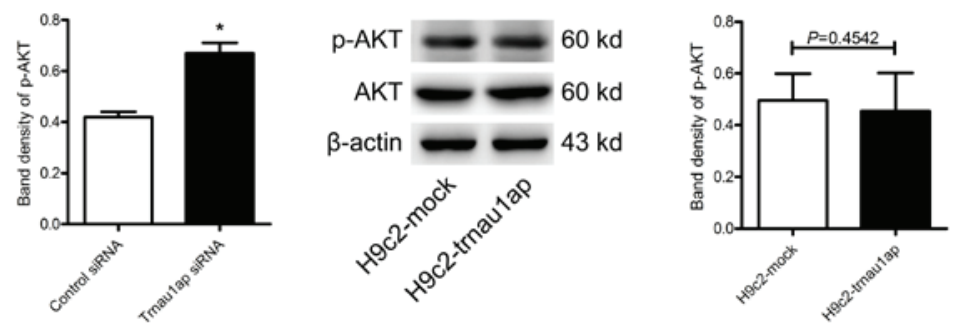

Figure 4. Effects of modulating Trnaulap expression levels on the expression of apoptosis-associated proteins. Protein expression levels of Bax and Bcl-2 in (A) Trnaulap-underexpressing, and (B) Trnaulap-overexpressing, cells were measured by western blotting. $\beta$-actin served as an internal control. The band densities of AKT and p-AKT in (C) Trnaulap-underexpressing and (D) Trnaulap-overexpressing cells were measured by western blotting. $\beta$-actin served as an internal control. The expression levels of $\mathrm{p}-\mathrm{AKT}$ were normalized against total AKT. All data are presented as the mean \pm standard deviation $\left(\mathrm{n}=3\right.$ ). ${ }^{*} \mathrm{P}<0.05$ and ${ }^{* *} \mathrm{P}<0.01$ vs. control siRNA or H9c2-Mock. Trnau1ap, transfer RNA selenocysteine 1 associated protein 1; p, phosphorylated; AKT, protein kinase B; Bax, Bcl-2-X-associated protein; Bcl-2, B-cell lymphoma 2; siRNA, small interfering RNA; ns, non-significant. 
whereasBcl-2 expression levels were downregulated, in the underexpression group compared with the control group (Fig. 4A, $\mathrm{P}<0.05$ for Bcl-2, $\mathrm{P}<0.01$ for Bax compared with H9c2-siRNA). By contrast, Bax expression levels were downregulated, while Bcl-2 expression levels were upregulated, in the overexpression group compared with mock-transfected cells (Fig. 4B, $\mathrm{P}<0.05$ for $\mathrm{Bcl}-2, \mathrm{P}<0.01$ for Bax compared with $\mathrm{H} 9 \mathrm{c} 2$-mock). In addition, the PI3K/AKT signaling pathway was activated in Trnaulap-underexpressing cells compared with control cells after $48 \mathrm{~h}$ transfection (Fig. 4C, $\mathrm{P}<0.05$ compared with H9c2-siRNA), although no significant differences were observed in Trnaulap-overexpressing compared with mock-transfected cells (Fig. 4D, $\mathrm{P}=0.4524$ compared with H9c2-mock).

\section{Discussion}

The present study demonstrated for the first time, to the best of our knowledge, that modulating expression levels of Trnaulap affected the proliferation and apoptosis of rat cardiomyocyte-like H9c2 cells. Knockdown of Trnaulap by siRNA inhibited proliferation and increased apoptosis. Mitochondrial membrane potential depolarization was observed in the Trnaulap knockdown cells. In addition, the PI3K/AKT pathway was activated in cells with reduced Trnaulap expression levels. In comparison, Trnaulap-overexpressing cells exhibited an increased proliferative capacity.

Trnaulap, additionally known as SECp43, is a highly conserved protein with two ribonucleoprotein-binding domains and a polar/acidic carboxy terminus, and is critical for selenoprotein synthesis (11). A previous study reported that a decrease in the expression levels of Trnaulap induced a downregulation of GPx1 expression levels, and co-knockdown of Trnaulap and SepSecS induced a decrease in selenoprotein expression levels (14). A recent study identified no significant alteration in the levels of ${ }^{75} \mathrm{Se}$-labeled hepatic proteins, or in levels of selenoproteins as determined by western blot analysis, in hepatocyte-specific Trnaulap knockout mice (19). However, in the present study, knockdown of Trnaulap in H9c2 cells reduced GPx1, Txnrd1 and SelK expression levels, and overexpression of Trnaulap increased selenoprotein expression levels, indicating that Trnaulap serves an important role in selenoprotein production. This discrepancy in findings suggests that the functional role of Trnaulap may vary according to tissue type and species.

Various selenoproteins are crucial antioxidant enzymes, including GPxs, TrxRs, SelK and selenoprotein W. Therefore, a decrease in selenoprotein expression levels, as in the Trnaulap knockdown group, may disturb cellular redox homeostasis, eventually leading to apoptosis.

PCNA, an essential cofactor of DNA polymerases, encircles synthesizing DNA and is used as a molecular marker of cell proliferation $(20,21)$. Numerous studies have reported that the proliferation of cells and tissues is associated with PCNA levels (22-24). In the present study, PCNA levels were increased in Trnaulap-overexpressing cells, suggesting that a potential association exists between Trnaulap and cell proliferation.

Mitochondria serve critical roles in oxygen free radical detoxification (25). Furthermore, these organelles are important for apoptosis. When pro-apoptotic proteins, including
Bax and BH3 interacting-domain death agonist, translocate to the mitochondrial membrane, mitochondrial permeability transition pores promote cytochrome c release, triggering apoptosis (26). The present study revealed that mitochondrial membrane depolarization occurred in cells with decreased Trnaulap expression levels, suggesting that a reduction in Trnaulap levels promoted apoptosis via the mitochondrial pathway.

Apoptosis is an important cellular process during development, and is additionally involved in tissue homeostasis by eliminating damaged cells. Furthermore, apoptosis is involved in numerous diseases, including cardiovascular disease (27). Caspase (cysteine aspartase) family members serve primary roles in programmed cell death. In apoptosis, activation of caspase- 3 is a critical event in the execution phase. $\mathrm{Bcl}-2$ family proteins are key regulators of the apoptotic signaling pathway. The pro- and anti-apoptotic Bcl-2 family members present on the mitochondrial membrane determine apoptosis or survival (28). Bcl-2 is an anti-apoptotic protein, while Bax is pro-apoptotic. Numerous studies have revealed that the $\mathrm{Bax} / \mathrm{Bcl}-2$ ratio is an important determinant of whether cells undergo apoptosis (29-31).

Previous studies have demonstrated that selenium protects neuroblastoma cells from hypoxia-induced apoptosis (32), and additionally protects primary human keratinocytes from apoptosis induced by exposure to ultraviolet radiation (33). The present study revealed that reducedTrnaulap expression levels inhibited proliferation and induced apoptosis, suggesting that this protein regulates proliferation and apoptosis in $\mathrm{H} 9 \mathrm{c} 2$ cells via its essential role in selenoprotein synthesis.

The PI3K/AKT signaling pathway serves a critical role in mediating survival and apoptosis $(34,35)$. Oxidative stress has been demonstrated to activate the PI3K/AKT signaling pathway in a variety of cells (36). A previous study revealed that the PI3K/AKT signaling pathway was activated in the muscles of selenium-deficient chickens (37). The present study identified that the PI3K/AKT signaling pathway was activated in cells with reducedTrnaulap expression levels. This finding suggests that the downregulation of selenoprotein synthesis may induce apoptosis via increased levels of oxidative stress.

In conclusion, to the best of our knowledge, these results demonstrated for the first time that Trnaulap regulated proliferation and the mitochondrial apoptotic pathway in cardiomyocyte-like cells. However, additional studies using other cell types and species are required to clarify the functional roles of Trnaulap. Nonetheless, these findings provide insight into the mechanisms underlying myocardial injury induced by selenium deficiency.

\section{Acknowledgements}

The present study was supported by the National Natural Science Foundation of China (grant nos. 81172616 and 81472929).

\section{References}

1. Lu J and Holmgren A: Selenoproteins. J Biol Chem 284: 723-727, 2009.

2. Combs GF Jr: Biomarkers of selenium status. Nutrients 7: 2209-2236, 2015 
3. Rayman MP: Selenium and human health. Lancet 379 : 1256-1268, 2012.

4. Mehdi Y, Hornick JL, Istasse L and Dufrasne I: Selenium in the environment, metabolism and involvement in body functions. Molecules 18: 3292-3311, 2013.

5. Turanov AA, Xu XM, Carlson BA, Yoo MH, Gladyshev VN and Hatfield DL: Biosynthesis of selenocysteine, the 21st amino acid in the genetic code, and a novel pathway for cysteine biosynthesis. Adv Nutr 2: 122-128, 2011

6. Metanis N and Hilvert D: Natural and synthetic selenoproteins. Curr Opin Chem Biol 22: 27-34, 2014.

7. Huang Z, Rose AH and Hoffmann PR: The role of selenium in inflammation and immunity: From molecular mechanisms to therapeutic opportunities. Antioxid Redox Signal 16: 705-743, 2012 .

8. Reeves MA and Hoffmann PR: The human selenoproteome: Recent insights into functions and regulation. Cell Mol Life Sci 66: 2457-2478, 2009.

9. Diamond AM: The subcellular location of selenoproteins and the impact on their function. Nutrients 7: 3938-3948, 2015.

10. Squires JE and Berry MJ: Eukaryotic selenoprotein synthesis: Mechanistic insight incorporating new factors and new functions for old factors. IUBMB Life 60: 232-235, 2008.

11. Ding F and Grabowski PJ: Identification of a protein component of a mammalian tRNA(Sec) complex implicated in the decoding of UGA as selenocysteine. RNA 5: 1561-1569, 1999.

12. Small-Howard A, Morozova N, Stoytcheva Z, Forry EP Mansell JB, Harney JW, Carlson BA, Xu XM, Hatfield DL and Berry MJ: Supramolecular complexes mediate selenocysteine incorporation in vivo. Mol Cell Biol 26: 2337-2346, 2006.

13. Papp LV, Lu J, Holmgren A and Khanna KK: From selenium to selenoproteins: Synthesis, identity, and their role in human health. Antioxid Redox Signal 9: 775-806, 2007.

14. Xu XM, Mix H, Carlson BA, Grabowski PJ, Gladyshev VN, Berry MJ and Hatfield DL: Evidence for direct roles of two additional factors, SECp43 and soluble liver antigen, in the selenoprotein synthesis machinery. J Biol Chem 280: 41568-41575, 2005

15. Oropeza-Moe M, Wisløff $\mathrm{H}$ and Bernhoft A: Selenium deficiency associated porcine and human cardiomyopathies. J Trace Elem Med Biol 31: 148-156, 2015.

16. Rose AH and Hoffmann PR: Selenoproteins and cardiovascular stress. Thromb Haemost 113: 494-504, 2015.

17. Cui J, Zhong R, Chu E, Zhang XF, Zhang WG, Fang CF, Dong Q, $\mathrm{Li}$ FL and Li H: Correlation between oxidative stress and L-type calcium channel expression in the ventricular myocardia of selenium-deficient mice. J Int Med Res 40: 1677-1687, 2012.

18. Livak KJ and Schmittgen TD: Analysis of relative gene expression data using real-time quantitative PCR and the 2(-Delta Delta C(T)) Method. Method 25: 402-408, 2001.

19. Mahdi Y, Xu XM, Carlson BA, Fradejas N, Günter P, Braun D, Southon E, Tessarollo L, Hatfield DL and Schweizer U: Expression of selenoproteins is maintained in mice carrying mutations in SECp43, the tRNA selenocysteine 1 associated protein (Trnaulap). PLoS One 10: e0127349, 2015.

20. Wang SC: PCNA: A silent housekeeper or a potential therapeutic target? Trends Pharmacol Sci 35: 178-186, 2014.
21. Moldovan GL, Pfander B and Jentsch S: PCNA, the maestro of the replication fork. Cell 129: 665-679, 2007.

22. Ip C, Thompson HJ and Ganther HE: Selenium modulation of cell proliferation and cell cycle biomarkers in normal and premalignant cells of the rat mammary gland. Cancer Epidemiol Biomarkers Prev 9: 49-54, 2000.

23. Chen JH, Tsou TC, Chiu IM and Chou CC: Proliferation inhibition, DNA damage, and cell-cycle arrest of human astrocytoma cells after acrylamide exposure. Chem Res Toxicol 23 : 1449-1458, 2010

24. Zeng H: Selenium as an essential micronutrient: Roles in cell cycle and apoptosis. Molecules 14: 1263-1278, 2009.

25. Buettner GR: Superoxide dismutase in redox biology: The roles of superoxide and hydrogen peroxide. Anticancer Agents Med Chem 11: 341-346, 2011

26. Orrenius S, Gogvadze V and Zhivotovsky B: Calcium and mitochondria in the regulation of cell death. Biochem Biophys Res Commun 460: 72-81, 2015.

27. Hotchkiss RS, Strasser A, McDunn JE and Swanson PE: Cell death in disease: Mechanisms and emerging therapeutic concepts. N Engl J Med 361: 1570-1583, 2009.

28. Brenner D and Mak TW: Mitochondrial cell death effectors Curr Opin Cell Biol 21: 871-877, 2009.

29. Zhang X, Chen Y, Gao B, Luo D, Wen Y and Ma X: Apoptotic effect of koumine on human breast cancer cells and the mechanism involved. Cell Biochem Biophys 72: 411-416, 2015.

30. Zhang WG, Chen L, Dong Q, He J, Zhao HD, Li FL and Li H: Mmu-miR-702 functions as an anti-apoptotic mirtron by mediating ATF6 inhibition in mice. Gene 531: 235-242, 2013.

31. Zhang W, Yu J, Dong Q, Zhao H, Li F and Li H: A mutually beneficial relationship between hepatocytes and cardiomyocytes mitigates doxorubicin-induced toxicity. Toxicol Lett 227: 157-163, 2014.

32. Sarada SK, Himadri P, Ruma D, Sharma SK, Pauline T and Mrinalini: Selenium protects the hypoxia induced apoptosis in neuroblastoma cells through upregulation of $\mathrm{Bcl}-2$. Brain Res 1209: 29-39, 2008.

33. Rafferty TS, Beckett GJ, Walker C, Bisset YC and McKenzie RC: Selenium protects primary human keratinocytes from apoptosis induced by exposure to ultraviolet radiation. Clin Exp Dermatol 28: 294-300, 2003.

34. Burgering BM and Coffer PJ: Protein kinase B (c-Akt) in phosphatidylinositol-3-OH kinase signal transduction. Nature 376: 599-602, 1995

35. Franke TF, Yang SI, Chan TO, Datta K, Kazlauskas A, Morrison DK, Kaplan DR and Tsichlis PN: The protein kinase encoded by the Akt proto-oncogene is a target of the PDGF-activated phosphatidylinositol 3-kinase. Cell 81: 727-736, 1995.

36. Martindale JL and Holbrook NJ: Cellular response to oxidative stress: Signaling for suicide and survival. J Cell Physiol 192: $1-15,2002$.

37. Huang JQ, Ren FZ, Jiang YY, Xiao C and Lei XG: Selenoproteins protect against avian nutritional muscular dystrophy by metabolizing peroxides and regulating redox/apoptotic signaling. Free Radic Biol Med 83: 129-138, 2015. 